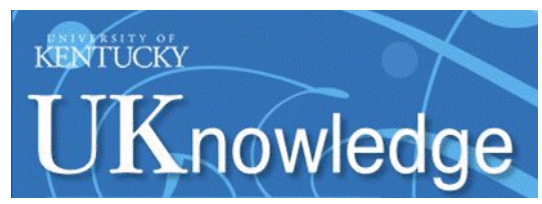

University of Kentucky

UKnowledge

$12-2017$

\title{
Physical Aggressiveness and Gray Matter Deficits in Ventromedial Prefrontal Cortex
}

\author{
David S. Chester \\ Virginia Commonwealth University \\ Donald R. Lynam \\ Purdue University \\ Richard Milich \\ University of Kentucky, richard.milich@uky.edu \\ C. Nathan DeWall \\ University of Kentucky, nathan.dewall@uky.edu
}

Follow this and additional works at: https://uknowledge.uky.edu/psychology_facpub

Part of the Behavior and Behavior Mechanisms Commons, Neuroscience and Neurobiology

Commons, and the Psychology Commons

Right click to open a feedback form in a new tab to let us know how this document benefits you.

\section{Repository Citation}

Chester, David S.; Lynam, Donald R.; Milich, Richard; and DeWall, C. Nathan, "Physical Aggressiveness and Gray Matter Deficits in Ventromedial Prefrontal Cortex" (2017). Psychology Faculty Publications. 170. https://uknowledge.uky.edu/psychology_facpub/170

This Article is brought to you for free and open access by the Psychology at UKnowledge. It has been accepted for inclusion in Psychology Faculty Publications by an authorized administrator of UKnowledge. For more information, please contact UKnowledge@lsv.uky.edu. 


\title{
Physical Aggressiveness and Gray Matter Deficits in Ventromedial Prefrontal Cortex
}

\author{
Digital Object Identifier (DOI) \\ https://doi.org/10.1016/j.cortex.2017.09.024 \\ Notes/Citation Information \\ Published in Cortex, v. 97, p. 17-22. \\ (c) 2017 Elsevier Ltd. All rights reserved.
}

This manuscript version is made available under the CC-BY-NC-ND 4.0 license https://creativecommons.org/licenses/by-nc-nd/4.0/.

The document available for download is the author's post-peer-review final draft of the article. 
Published in final edited form as:

Cortex. 2017 December ; 97: 17-22. doi:10.1016/j.cortex.2017.09.024.

\title{
Physical Aggressiveness and Gray Matter Deficits in Ventromedial Prefrontal Cortex
}

\author{
David S. Chester ${ }^{1,{ }^{*}}$, Donald R. Lynam ${ }^{2}$, Richard Milich ${ }^{3}$, and C. Nathan DeWall ${ }^{3}$ \\ ${ }^{1}$ Department of Psychology, Virginia Commonwealth University, USA \\ ${ }^{2}$ Department of Psychological Sciences, Purdue University, USA \\ ${ }^{3}$ Department of Psychology, University of Kentucky, USA
}

\begin{abstract}
What causes individuals to hurt others? Since the famous case of Phineas Gage, lesions of the ventromedial prefrontal cortex (VMPFC) have been reliably linked to physically aggressive behavior. However, it is unclear whether naturally-occurring deficits in VMPFC, among normal individuals, might have widespread consequences for aggression. Using voxel based morphometry, we regressed gray matter density from the brains of 138 normal female and male adults onto their dispositional levels of physical aggression, verbal aggression, and sex, simultaneously. Physical, but not verbal, aggression was associated with reduced gray matter volume in the VMPFC and to a lesser extent, frontopolar cortex. Participants with less gray matter density in this VMPFC cluster were much more likely to engage in real-world violence. These findings suggest that even granular deficits in normal individuals' VMPFC gray matter can promote physical aggression.
\end{abstract}

\section{Keywords}

aggression; gray matter; ventromedial prefrontal cortex; voxel based morphometry

Aggression has remained in the human behavioral repertoire despite substantial cultural advances. Physical aggression, in which aggressors seek to harm others' bodies against their will, is a remarkably pernicious and costly form of aggression (Anderson and Bushman 2002). The stubborn and tenacious nature of such behavior suggests that physical aggression arises, in part, due to alterations in individuals' underlying brain structure. To date, investigations of physical aggression's neuro-structural underpinnings have focused on the small percentage of the population that comprises clinically- and criminally-aggressive populations. However, limiting such investigation to these populations ignores physical aggression's continuous nature, which exhibits substantial individual differences across

\footnotetext{
"Correspondence should be addressed to: David S. Chester, 302 Thurston House, 808 West Franklin St., Department of Psychology, Virginia Commonwealth University, Richmond, VA, 23284, USA, dschester@ vcu.edu, Phone: 1-804-828-7624, Facsimile: 1-804-828-2237.

Publisher's Disclaimer: This is a PDF file of an unedited manuscript that has been accepted for publication. As a service to our customers we are providing this early version of the manuscript. The manuscript will undergo copyediting, typesetting, and review of the resulting proof before it is published in its final citable form. Please note that during the production process errors may be discovered which could affect the content, and all legal disclaimers that apply to the journal pertain.
} 
humankind. In the present research, we sought to assess the gray matter correlates of physical aggressiveness in a relatively large sample of normal young adults.

\section{The VMPFC and Aggression}

\section{Evidence from lesion patients, violent criminals, and aggressive psychopathology}

Extending back to the famous case of Phineas Gage, injuries of the brain's frontal lobe have shown how readily physical aggressiveness can emerge from structural damage to the brain (Damasio et al. 1994). Indeed, one of the most common biological causes of aggressive behavior is lesions of the brain's frontal lobe (Tateno et al. 2003). Combat veterans with lesions of the ventromedial prefrontal cortex (VMPFC) exhibited substantially greater aggressive behavior than individuals with lesions of other brain regions or no brain lesions (Grafman et al. 1996). VMPFC dysfunction reliably differentiates violent from non-violent criminal offenders (Bufkin and Luttrell 2005). Individuals diagnosed with intermittent explosive disorder exhibited reduced VMPFC activity and VMPFC-amygdala connectivity while viewing angry faces (Coccaro et al. 2007). Across these samples of violent patients and offenders, the VMPFC appears to play a clear and causal role in promoting physical violence.

\section{Functional evidence from normal adults}

Empirical support for the link between VMPFC deficits and physical aggression does not purely come from studies of lesion patients, violent criminals, and individuals diagnosed with violent psychopathology. Normal young adults who imagined an aggressive act exhibited reduced cerebral blood flow in the VMPFC, as compared to when they imagined a non-violent act (Pietrini et al. 2000). Among a similar population, VMPFC activity was negatively associated with financial forms of aggression during behavioral economics (Mehta and Beer 2009). VMPFC reactivity to aggressive interactions was selective for prosocially reacting to the opponent's suffering due to the aggression (Lotze et al. 2007). However, these studies used functional neuroimaging, leaving unexplored the structural basis of physical aggression among normal individuals. The current research fills this gap in the literature by providing a comprehensive test of the hypothesis that normal individuals' aggressiveness and real-world aggressive behavior relates to structural deficits in the VMPFC.

\section{Overview}

Based on previous research implicating VMPFC deficits in the promotion of physical aggression, we predicted that normal, young adults' dispositional physical aggression would be associated with reduced gray matter in this region. To test this hypothesis, participants had a high-resolution structural scan taken of their brain using magnetic resonance imaging (MRI) and then reported their trait levels of physical and verbal aggressiveness, as well as their sex. These two latter variables served as crucial covariates to assure our results were specific for trait physical aggression. As an additional outcome measure, a subset of participants reported whether they had ever previously been in a physical fight. We predicted 
that VMPFC gray matter density would be inversely associated with prior engagement in physical fights.

\section{Materials and Methods}

\section{Participants}

Participants were 138 normal, right-handed, young adults ( 91 females, 47 males; age: $M=$ $19.42, S D=2.10$, range: $18-30$ ). This sample size is quite large for an MRI analysis that tested a brain-behavior correlation and was determined by combining participants from two existing MRI datasets that contained our study variables. As such, sample size was not determined based on a power analysis, but on the available data. Participant enrollment occurred using the stop rule of reaching 60 participants in the first dataset and 80 participants in the second dataset.

Participants were either undergraduates recruited through the introductory psychology subject pool in exchange for credit towards their course's research requirement and an image of their brain or general community members recruited in exchange for money and an image of their brain. Potential candidates were excluded from the study if they met any of the following criteria as assessed by an online questionnaire: any major medical conditions, developmental disorders, body mass index above 30, claustrophobia, current or past neurological or psychiatric disorder, metallic objects in the body, prior head trauma, and psychoactive medication use.

\section{Materials}

Brief Aggression Questionnaire-To measure trait physical aggression, we employed the Brief Aggression Questionnaire (Webster et al. 2014). The Brief Aggression Questionnaire contains twelve items that comprise four factors: anger (sample item: I have trouble controlling my temper), hostility (sample item: I sometimes feel that people are laughing at me behind my back), physical aggression (sample item: Given enough provocation, I may hit another person), and verbal aggression (sample item: My friends say that I'm somewhat argumentative). Participants responded to each item along a 1 (disagree) to 7 (agree) Likert-type scale.

\section{Procedure}

Participants arrived at the University of Kentucky's Magnetic Resonance Imaging and Spectroscopy Center where they had the study explained to them and were screened to ensure they would be safe and comfortable in the MRI environment. Participants were then placed in an MRI scanner and had a high-resolution structural scan taken of their brain. Participants then exited the scanner and completed a battery of questionnaires including the Brief Aggression Questionnaire and a demographics survey. A sub-sample $(N=64)$ also completed a single item measure of actual physically aggressive behavior, in which they answered 'yes' or 'no' to the item "Have you ever been in a physical fight?" Yes responses were coded as 1 and No responses were coded as 0 . Finally, all participants were debriefed and dismissed. 


\section{MRI Data Acquisition}

All MRI data were obtained using a 3.0 Tesla Siemens Magnetom Trio scanner. Structural images consisted of a T1-weighted MP-RAGE scan: $1 \mathrm{~mm}^{3}$ isotropic voxel size, echo time $=$ $2.56 \mathrm{~ms}$, repetition time $=1.69 \mathrm{~s}$, flip angle $=12^{\circ}$.

\section{Statistical Analyses}

Data necessary to reproduce all analyses from this project have been made publicly available at https://osf.io/v42w6/, excepting statistical brain maps, which are available upon request.

Predicting aggressive behavior from trait measures-Using multiple logistic regression, we simultaneously modeled trait physical aggression and trait verbal aggression as predictors of having been in a physical fight. Sex was later added to this model as a covariate.

Gray matter analyses-The Oxford Centre for Functional MRI of the Brain (FMRIB)'s Software Library (FSL version 5.0) was used to conduct all pre-processing and voxel based morphometry analyses (Smith et al. 2004; Woolrich et al. 2009). To assess gray matter density, we used voxel based morphometry (VBM). Structural data was analyzed with FSLVBM (Douaud et al. 2007, http://fsl.fmrib.ox.ac.uk/fsl/fslwiki/FSLVBM), an optimized VBM protocol (Good et al. 2001). First, structural images were brain-extracted and gray matter-segmented before being registered to the Montreal Neurological Institute (MNI 152) standard space using non-linear registration (Andersson et al. 2007). The resulting images were averaged and flipped along the $\mathrm{x}$-axis to create a left-right symmetric, study-specific gray matter template. Second, all native gray matter images were non-linearly registered to this study-specific template and "modulated" to correct for local expansion (or contraction) due to the non-linear component of the spatial transformation. The modulated gray matter images were then smoothed with an isotropic Gaussian kernel $(\sigma=3.5 \mathrm{~mm})$. Finally, a voxelwise general linear model, was applied in which we simultaneously modeled trait physical aggression, trait verbal aggression, and sex. Sex was included as a covariate due to reliable sex differences in brain structure that also appeared in this study sample (see sex difference analysis below). Contrast maps comparing each variable's partial correlation to the null hypothesis were corrected for multiple comparisons across all voxels using nonparametric threshold free cluster enhancement (via the Randomise command; 5,000 permutations per contrast). Voxel significance was determined at the corrected $p<.05$ threshold.

Predicting aggressive behavior from gray matter-For each participant, average gray matter density estimates were extracted from and averaged across all significant voxels of the VMPFC cluster. Using multiple logistic regression, we simultaneously modeled trait physical aggression, trait verbal aggression, and sex as predictors of gray matter density in the VMPFC cluster. Using multiple logistic regression, we simultaneously modeled gray matter density as a predictor of having been in a physical fight. Sex was later added to this model as a covariate. 


\section{Results}

\section{Descriptive Statistics}

We calculated Physical Aggression and Verbal Aggression subscale scores of the Brief Aggression Questionnaire by averaging across each participant's corresponding responses. Both the Physical Aggression, Cronbach's $a=.80$, and Verbal Aggression, Cronbach's $a=$. 66, subscales exhibited adequate internal consistency. Physical Aggression subscale scores exhibited substantial variability across the scale's possible 1 to 7 range, $M=2.54, S D=$ 1.52 , observed range $=1.00-7.00$. Verbal Aggression subscale scores exhibited substantial variability across the scale's possible 1 to 7 range, $M=3.70, S D=1.33$, observed range = $1.33-7.00$.

Sixty-four participants answered the question regarding whether they had ever been in a physical fight, 44 reported 'no' and 20 reported 'yes'. Bolstering the validity of our trait aggression questionnaire, trait physical aggression scores were associated with a higher likelihood of having been in a physical fight, $B=0.67$ [0.25, 1.65], $S E=0.27, O . R .=1.95$, $X(1)=8.15, p=.004$, yet there was no significant association with trait verbal aggression, $B$ $=0.23[-0.15,0.69], S E=0.23, O . R .=1.26, X(1)=1.35, p=.246$. This effect of trait physical aggression on greater likelihood of being in a fight held even after controlling for sex, $B=0.63[0.06,1.79], S E=0.26, O . R .=1.88, X(1)=5.98, p=.014$.

\section{Voxel Based Morphometry and Whole-Brain Regression Analyses}

Trait physical aggression (controlling for verbal aggression and sex) was negatively associated with gray matter density in a single cluster in Brodmann's Areas (BA) 10 and 11; peak voxel: $t=-5.08, p=.023$, MNI coordinates $(x, y, z)=6,54,-4 ; 67$ contiguous voxels; Figure 1. Assignment to BA 10 and 11 was conducted using MRIcroN's Brodmann's Atlas based on Damasio and Damasio's (1989) original template (http://www.cabiatl.com/mricro/ mricro/lesion.html\#brod). This cluster was largely localized to the portions of BA 10 and 11 that are considered VMPFC (Delgado, Beer, Fellows, Huettel, Platt, Quirk, \& Schiller, 2016; Myers-Schulz \& Koenigs, 2012; Öngür, Ferry, \& Price, 2003), though several voxels did extend beyond the internal frontal sulcus to portions of BA 10 deemed frontopolar cortex (Myers-Schulz \& Koenigs, 2012). Given that the vast majority of voxels were within VMPFC (and the small number of voxels outside of it), we refer to this reduced gray matter cluster as localized to the VMPFC. This VMPFC anatomical assignment was further bolstered by a reverse inference meta-analysis performed using NeuroSynth (neurosynth.org; Yarkoni, Poldrack, Nichols, Van Essen, \& Wager, 2011) on fMRI correlates of the term 'ventromedial prefrontal', which demonstrated that the peak voxel from this cluster was well within the VMPFC, $N=250$ studies, $Z=7.34$. The effect of physical aggressiveness on gray matter estimates was even further localized to the VMPFC as this Physical Aggression scores from the BAQ were unassociated with whole-brain gray matter, $B=.00[-.00, .00], t(136)=-0.47, p=.636$. Follow-up analyses including the Anger and Hostility subscales of the BAQ revealed no significant gray matter correlates of either of these measures. 
Gray matter estimates were then extracted from this cluster and entered into subsequent regression analyses to obtain effect size estimates. Trait physical aggression was negatively associated with VMPFC gray matter density estimates, $B=-.03[-.04,-.02], t(134)=$ $-5.08, p<.001$, Figure 2 , whereas trait verbal aggression was marginally and positively association with such gray matter estimates, $B=.01[.00, .02], t(134)=1.96, p=.052$. Sex (coded as $1=$ male, $0=$ female) was unassociated with these VMPFC gray matter estimates, $B=.01[-.02, .05], t(134)=0.61, p=.546$, were. Zero-order correlations for all variables are presented in Table 1.

Trait verbal aggression (controlling for trait physical aggression and sex) was not significantly associated with gray matter density in any voxel. Being male (controlling for trait physical and trait verbal aggression) was negatively associated with gray matter density across multiple brain regions, extending bilaterally across the caudate, nucleus accumbens, insula, thalamus, fusiform gyrus, and dorsolateral cerebellum, Table 2.

\section{Logistic Regression Modeling of Physical Fight Likelihood}

Gray matter density in the VMPFC cluster that was identified in the previous VBM analysis was associated with a substantially lower likelihood that participants had previously been in a physical fight, $B=-8.51[-17.55,-2.72], O . R .=0.0002, X(1,60)=6.51, p=.011$. This effect was maintained when sex was added as a covariate, $B=-7.80[-16.59,-2.48], O . R .=$ $0.0004, X(2,59)=5.41, p=.020$.

\section{Discussion}

Each day, seemingly normal people behave aggressively. They rarely have brain lesions, criminal records, or psychiatric diagnoses. Indeed, even among disordered populations, severe psychological symptoms (i.e., psychosis) do not reliably predict violence (Skeem et al. 2016). Yet the majority of previous research that has attempted to illuminate the structural brain basis of physical aggression have largely focused on lesion patients, violent criminals, and individuals diagnosed with aggressive psychopathology. This focus on extreme populations fails to accurately reflect the broad spectrum of physical aggressiveness. In the present research, we used voxel based morphometry in a relatively large sample of normal young adults to test the neuro-structural correlates of physical aggression.

In line with a host of previous research implicating structural and functional deficits in the ventromedial prefrontal cortex (VMPFC) as a reliable predictor of physical aggressiveness, we observed a negative association between trait physical aggression and gray matter density in the VMPFC. This effect was observed above-and-beyond verbal forms of aggression, arguing for the specificity of our findings to physical forms of aggression.

This reduced gray matter in the VMPFC could reflect deficits in a host of psychological processes, as the VMPFC is an integrative hub that performs many self-regulatory functions. Under the self-regulatory umbrella, the VMPFC subserves adaptive forms of emotionregulation (Davidson et al. 2000), self-relevance (Mitchell et al. 2005), and rewardprocessing (Haber and Knutson, 2009), amongst others. Any number or combination of 
these regulatory processes may thus be impaired in normal individuals with reduced VMPFC gray matter density.

Deficits in any of these regulatory processes would likely motivate physical aggression. For instance, emotion-regulation deficits arising from structural impairments in the VMPFC have been theorized to underpin aggressive behavior (Davidson et al. 2000). Structural deficits which link the VMPFC to other reward-circuit regions such as the ventral striatum have been linked to narcissistic tendencies (Chester et al. 2016). Narcissistic traits are positively linked to aggressive behavior (Bushman and Baumeister 1998), forming another putative mechanism through which structural VMPFC deficits might promote violence. Finally, the VMPFC plays a critical role in regulating the function of the ventral striatum, a key neural substrate of reward-processing (Haber and Knutson 2009). Ventral striatal activity that is exacerbated and de-coupled from the regulatory functions of the prefrontal cortex has been linked to greater physical aggression (Chester and DeWall, 2016). Therefore, structural deficits in the VMPFC may dysregulate the brain's reward response to aggression, reinforcing this behavior and serving to promote the physically aggressive phenotype we sought to better understand in this research. Unfortunately, we do not possess the data necessary to disentangle which, if any, of these putative mechanisms explain the correlation between trait physical aggression and VMPFC gray matter density. Future research should rigorously test each of these predictions.

Unexpectedly, we observed substantially less gray matter density across various brain regions among males as they compared to females. The span of these sex differences was remarkable and extended across many brain regions, each with myriad psychological functions. Primarily, the areas in which males showed less gray matter density were subcortical, with notable exceptions in the fusiform gyrus of the occipital cortex. These findings may have been impacted by the fact that females outnumbered males approximately two-to-one in our sample, so this caveat should be explicit in any interpretation of these preliminary results. Future research on structural brain differences between males and females should seek to replicate our findings and test what implications they have for sex differences in human behavior.

\section{Limitations and Future Directions}

A central component of the present research was to use a sample that was 'normal' from a biological standpoint. In doing so, we largely sampled from undergraduate populations which are not necessarily representative of the larger human species. Future research should seek to replicate our results in diverse populations, across cultures and other demographic features to ensure our results are not an artifact of our sampling population. Additionally, our findings are purely correlational. Longitudinal research, in which individuals' physical aggressiveness is repeatedly measured over longer spans of time, along with their gray matter density is required to better substantiate any causal claims.

\section{Conclusions}

When we watch human acts of violence on the nightly news or elsewhere, it is simple to dismiss such aggressive behavior as the exploits of a small group of people who have 
unusual biological, criminal, or psychological backgrounds. However, scientific research pulls away the curtain on this fantasy and instead reveals that across the spectrum of the human experience, the propensity for physical violence lurks within more of us than we would like to imagine. Neuroscientific research reifies this unpleasant thought experiment, yet allows for a hopeful outcome. If we can explicate the neural underpinnings of physically aggressive behavior, our species then has avenues through which it can be reduced. In the present research we have identified a specific neuro-structural correlate of physical aggression, gray matter deficiencies in the VMPFC, and hope that this discovery spurs on future investigation.

\section{Acknowledgments}

\section{Funding}

This work was supported by the National Institute on Drug Abuse (grant number redacted for blinded review), the Foundation for Personality and Social Psychology's Heritage Initiative, and the Robert S. Lipman Research Fund for the Prevention of Drug and Alcohol Abuse.

\section{References}

Anderson CA, Bushman BJ. Human aggression. Annual Review of Psychology. 2002; 53:27-51.

Andersson, JL., Jenkinson, M., Smith, S. Non-linear registration, aka Spatial normalisation FMRIB technical report TR07JA2. Vol. 2. FMRIB Analysis Group of the University of Oxford; 2007.

Bufkin JL, Luttrell VR. Neuroimaging studies of aggressive and violent behavior current findings and implications for criminology and criminal justice. Trauma, Violence, \& Abuse. 2005; 6:176-191.

Chester DS, DeWall CN. The pleasure of revenge: Retaliatory aggression arises from a neural imbalance towards reward. Social Cognitive and Affective Neuroscience. 2016; 11:1173-1182. [PubMed: 26117504]

Chester DS, Lynam DR, Powell DK, DeWall CN. Narcissism is associated with weakened frontostriatal connectivity: A DTI study. Social Cognitive and Affective Neuroscience. 2016; 11:1036-1040. [PubMed: 26048178]

Coccaro EF, McCloskey MS, Fitzgerald DA, Phan KL. Amygdala and orbitofrontal reactivity to social threat in individuals with impulsive aggression. Biological Psychiatry. 2007; 62:168-178. [PubMed: 17210136]

Damasio, H., Damasio, AR. Lesion analysis in neuropsychology. Oxford University Press; USA: 1989.

Damasio H, Grabowski T, Frank R, Galaburda AM, Damasio AR. The return of Phineas Gage: Clues about the brain from the skull of a famous patient. Science. 1994; 264:1102-1105. [PubMed: 8178168]

Davidson RJ, Putnam KM, Larson CL. Dysfunction in the neural circuitry of emotion regulation--a possible prelude to violence. Science. 2000; 289:591-594. [PubMed: 10915615]

Delgado MR, Beer JS, Fellows LK, Huettel SA, Platt ML, Quirk GJ, Schiller D. Viewpoints: Dialogues on the functional role of the ventromedial prefrontal cortex. Nature Neuroscience. 2016; 19:1545-1552. [PubMed: 27898086]

Douaud G, Smith S, Jenkinson M, Behrens T, Johansen-Berg H, Vickers J, James A. Anatomically related gray and white matter abnormalities in adolescent-onset schizophrenia. Brain. 2007; 130:2375-2386. [PubMed: 17698497]

Grafman J, Schwab K, Warden D, Pridgen A, Brown HR, Salazar AM. Frontal lobe injuries, violence, and aggression: A report of the Vietnam Head Injury Study. Neurology. 1996; 46:1231-1231. [PubMed: 8628458]

Haber SN, Knutson B. The reward circuit: Linking primate anatomy and human imaging. Neuropsychopharmacology. 2009; 35:4-26. 
Lotze M, Veit R, Anders S, Birbaumer N. Evidence for a different role of the ventral and dorsal medial prefrontal cortex for social reactive aggression: An interactive fMRI study. NeuroImage. 2007; 34:470-478. [PubMed: 17071110]

Mehta PH, Beer JS. Neural mechanisms of the testosterone-aggression relation: The role of orbitofrontal cortex. Journal of Cognitive Neuroscience. 2009; 22:2357-2368.

Mitchell JP, Banaji MR, Macrae CN. The link between social cognition and self-referential thought in the medial prefrontal cortex. Journal of Cognitive Neuroscience. 2005; 17:1306-1315. [PubMed: 16197685]

Myers-Schulz B, Koenigs M. Functional anatomy of ventromedial prefrontal cortex: implications for mood and anxiety disorders. Molecular Psychiatry. 2012; 17:132-141. [PubMed: 21788943]

Öngür D, Ferry AT, Price JL. Architectonic subdivision of the human orbital and medial prefrontal cortex. Journal of Comparative Neurology. 2003; 460:425-449. [PubMed: 12692859]

Pietrini P, Guazzelli M, Basso G, Jaffe K, Grafman J. Neural correlates of imaginal aggressive behavior assessed by positron emission tomography in healthy subjects. American Journal of Psychiatry. 2000; 157:1772-1781. [PubMed: 11058474]

Skeem J, Kennealy P, Monahan J, Peterson J, Appelbaum P. Psychosis uncommonly and inconsistently precedes violence among high-risk individuals. Clinical Psychological Science. 2016; 4:40-49.

Smith SM, Jenkinson M, Woolrich MW, Beckmann CF, Behrens TEJ, Johansen-Berg H, Matthews PM. Advances in functional and structural MR image analysis and implementation as FSL. NeuroImage. 2004; 23:S208-S219. [PubMed: 15501092]

Tateno A, Jorge RE, Robinson RG. Clinical correlates of aggressive behavior after traumatic brain injury. The Journal of Neuropsychiatry and Clinical Neurosciences. 2003; 15:155-160. [PubMed: 12724455]

Webster GD, Dewall CN, Pond RS, Deckman T, Jonason PK, Le BM, Bator RJ. The brief aggression questionnaire: Psychometric and behavioral evidence for an efficient measure of trait aggression. Aggressive Behavior. 2014; 40:120-139. [PubMed: 24115185]

Woolrich MW, Jbabdi S, Patenaude B, Chappell M, Makni S, Behrens T, Smith SM. Bayesian analysis of neuroimaging data in FSL. NeuroImage. 2009; 45:S173-186. [PubMed: 19059349] 

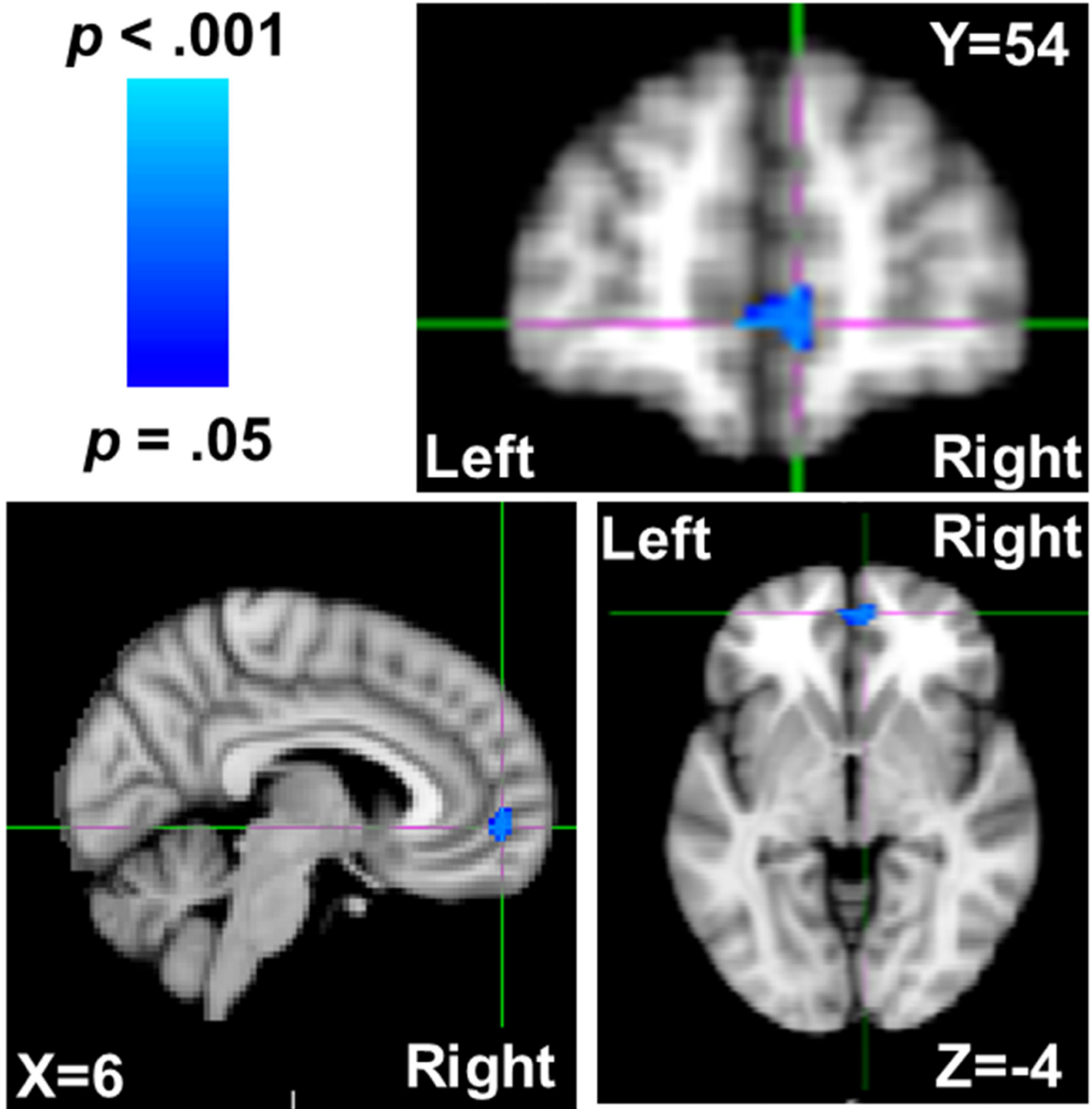

Figure 1.

VMPFC voxels that were negatively associated with trait physical aggression (as quantified by higher scores on the Brief Aggression Questionnaire's Physical Aggression subscale) depicted in blue, while controlling for trait verbal aggression and sex. Coordinates are in MNI space. 


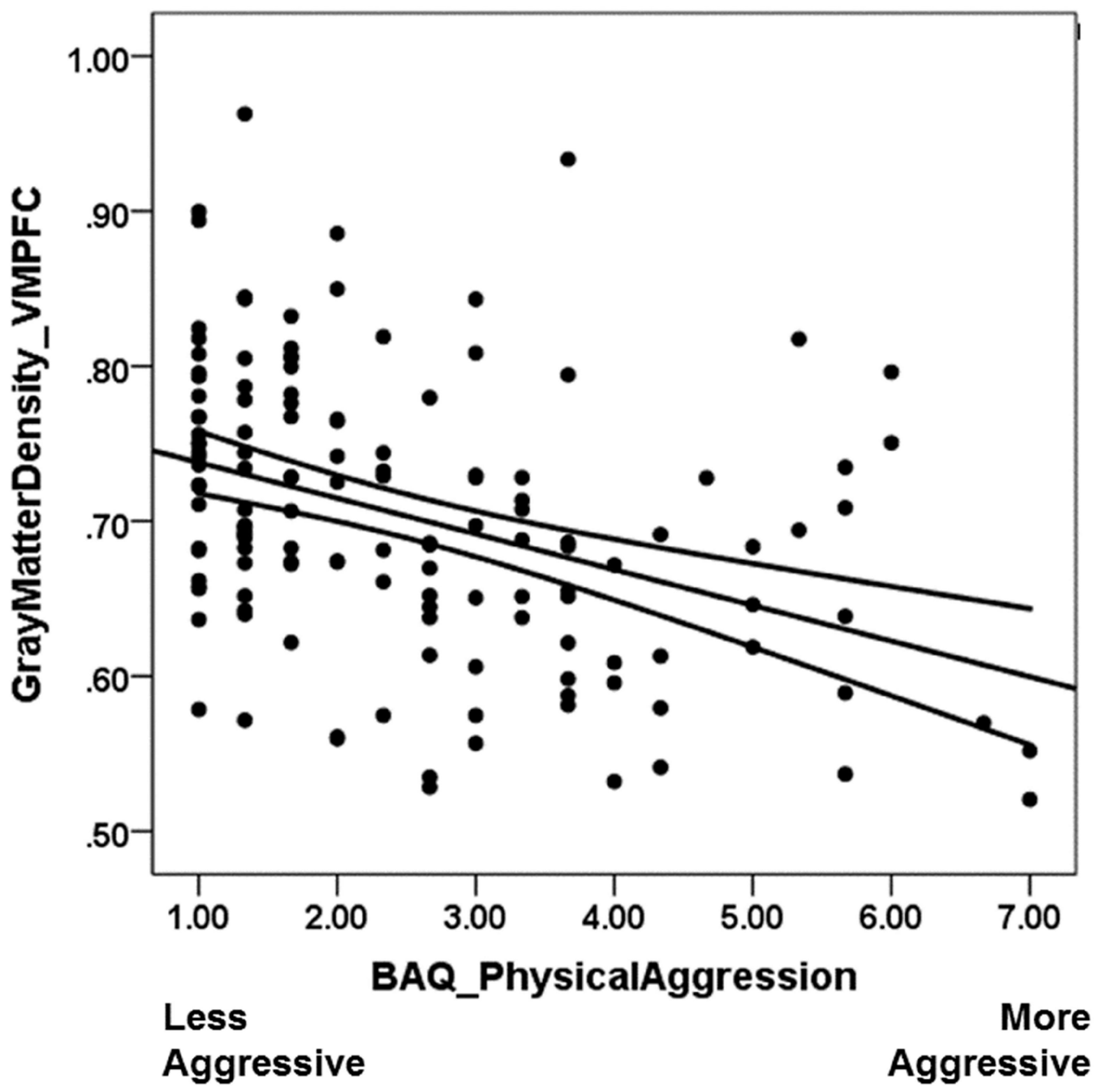

Figure 2.

Scatterplot and regression line depicting the negative correlation between trait physical aggression and gray matter density in the VMPFC. Curved lines represent the $95 \%$ confidence interval of the regression slope. 


\section{Table 1}

Zero-order correlations and 95\% confidence intervals (calculated via bias corrected and accelerated bootstrapping; 1,000 resamples) for all study variables.

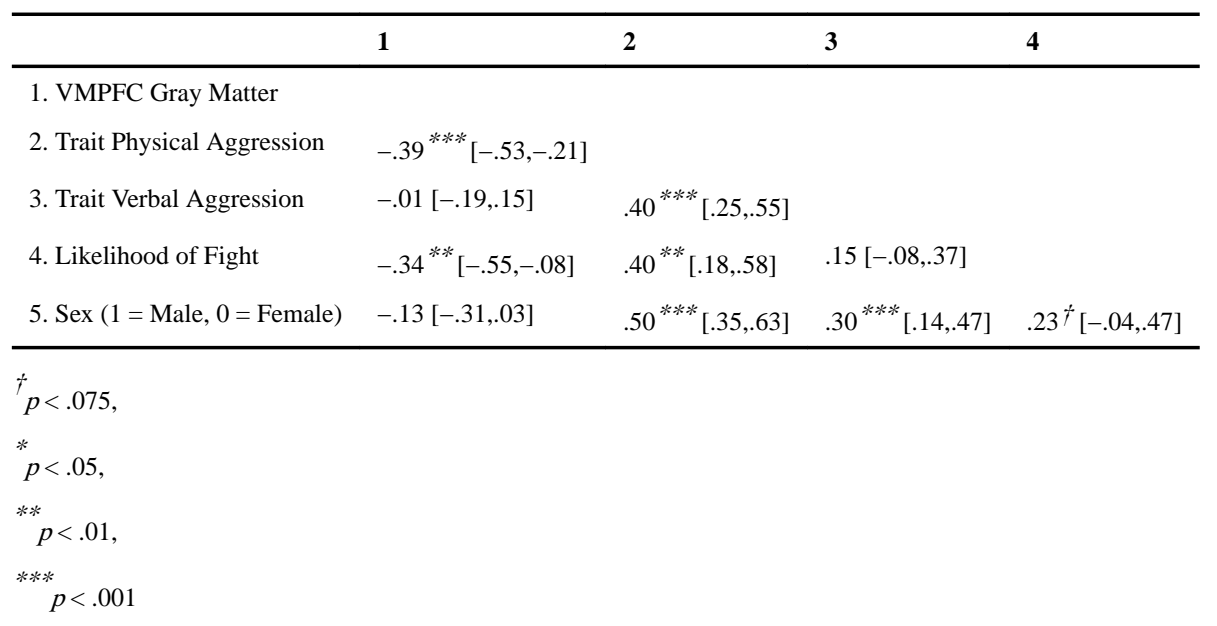




\section{Table 2}

Brain regions that were significantly, negatively associated with being male (as compared to being female). Coordinates are in MNI space.

\begin{tabular}{llll}
\hline Brain Region & Voxels & peak $\boldsymbol{t}$ & peak coordinates $(\mathbf{x}, \mathbf{y}, \mathbf{z})$ \\
\hline Accumbens/Caudate/Insula/Thalamus & 5,250 & -5.37 & $12,10,-10$ \\
Occipital Fusiform Gyrus/Cerebellum & 349 & -4.00 & $38,-72,-16$ \\
Cerebellum & 122 & -3.86 & $-40,-62,-28$ \\
Occipital Fusiform Gyrus & 98 & -3.57 & $-16,-78,-12$ \\
\hline
\end{tabular}

